\title{
Pakistani Semi-tribal/Tribal Women in War Zones: Displacement and Rehabilitation
}

\author{
Dr Farooq Hasnat ${ }^{*} \mathcal{E}$ \\ Dr Shehzadi Zamurrad Awan**
}

\section{Abstract}

Since 2002, Pakistan witnessed a prolonged insurgency in its tribal areas bordering Afghanistan. Since then, Pakistani armed forces are engaged in military operations against the militants. This conflict has a strong bearing on the inhabitants, especially women and children due to their vulnerable and marginalized placement in economically and structurally deprived tribal society. This research will be carried out from three angles. First, it will attempt to understand the centuries-old tribal customs and traditions, which confine women in an isolated and non-participatory role as compared to the mainstream of Pakistani women. The second dimension of this research is to compare and contrast the level of tribal woman's displacement in a conflict scenario. The third dimension of this research is to investigate the accumulated challenges of the tribal women in the displacement and rehabilitation process. It has been

* Dr Farooq Hasnat is Professor Political Science and International Relations. Former Chairman, Department of Political Science, University of Punjab, Lahore. Adjunct Scholar, Middle East Institute, Washington, D.C.; and also served as Chair at the Institute of Strategic Studies, Jordan University, Amman. He can be contacted at hasnatf@gmail.com

** Dr Shehzadi Zamurrad Awan is Associate Professor, Political Science Department, Forman Christian College (A Chartered University), Lahore.

@2021 by the Islamabad Policy Research Institute.

IPRI Journal XXI (2): 149-175

https://doi.org/10.31945/iprij.210206 
observed that after the military operation when the displaced women returned to their homes, they felt aliens in their ancestral houses. This Post-Traumatic Stress Disorder (PTSD) was a serious challenge for women and children as the socio-cultural dynamics of the tribal society hardly allow them to engage in various outdoor activities, including treatment through counselling from psychiatrists. To understand various socio-cultural problems of women, during and after the conflict, apart from secondary resources, a focused-group discussion with male respondents from Swat and Waziristan was conducted. In this study, their responses have helped in confirming and reinforcing the arguments as a primary source. To conclude one may say that although women and children are most affected in conflict situations, however, the gravity of their miseries could be diluted by proper planning and timely decisions by the relevant authorities.

Keywords: Swat, Conflict, Women, Waziristan, Pakistan. Displacement, Rehabilitation 


\section{Introduction}

Oince 2002, Pakistan's armed forces are engaged in a military operation against militant Afghans, as well as the Pakistani Taliban in both (the then) Provincially Administered Tribal Areas (PATA) ${ }^{1}$ and Federally Administered Tribal Areas (FATA) ${ }^{2}$. This particular conflict, as generally analyzed has a strong bearing on the inhabitants, especially women and children of the settled area of Swat and tribal Waziristan, because of their vulnerable and already marginalized placement in economically and structurally deprived tribal society. During a variety of military operations in the tribal areas, the civilian population got entangled in the crossfire. As a result, the federal government decided to evacuate the non-combatant population, which largely comprised of women and children to safer places, away from the battle zones. According to Internal Displacement Monitoring Centre, in 2008, 232,700 and 200,000 IDPs (Internally Displaced Persons) were estimated, during September and December, respectively. From 2007 to 2009, more than 550,000 inhabitants were either evacuated or were voluntarily displaced

1 PATA area of Pakistan consists of four former princely states as well as tribal areas and tribal territories in districts from Khyber-Pakhtunkhwa and Balochistan. PATA areas from Khyber-Pakhtunkhwa include Chitral District (former Chitral state), Upper Dir District (former Dir state), Lower Dir District (former Dir state), Swat District (former Swat state including Kalam), Buner District, Shangla District, Kohistan District, Kala Dhaka District, Malakand and Tribal Area adjoining Mansehra District (Battagram, Allai and Upper Tanawalormer) and former Amb state. The PATA areas from Balochistan includesnclude, Zhob District, Killa Saifullah District, Musakhel District, Sherani District, Loralai District, Barkhan District, Kohlu District, DeraBugti District and Dalbandin Tehsil of Chagai District. PATA is also known as a settled area. The focus of military operations remained Swat Valley and Shanglas district, wherein the result of military operation, Rah-e-Haq-I (2007), Rah-e-Haq-II (2007), Rah-e-Haq III (2008), Black Thunderstorm (2008) and Rah-e-Rast (2009) a significant number of people were displaced.

2 FATA area of Pakistan occupies 32,000 square kilometers of land and is the residence of approximately 4.453 million people, divided into seven administrative tribal agencies: Bajaur, Mohmand, Khyber, Orakzai, Kurram, North and South Waziristan. The name of military operations in FATA is Sher Dil-2008 in Bajur, Sirat-Mustaqeem-2008 in Khyber, Rah-e-Najat-2009 in South Waziristan, Brekhna-2009 in Mohammad, Zarb-Azb-2014 in North Waziristan. These operations displaced a significant number of people. 


\section{Dr Farooq Hasnat \& Dr Shehzadi Zamurrad Awan}

from these areas. This paper attempts to investigate the plight of displaced women of the above mentioned two areas, realizing their gender-related socio-cultural handicaps and under-development.

To understand the various socio-cultural problems of these women, during and after the conflict, apart from secondary resources, a focused-group discussion with male respondents from Swat and Waziristan was conducted.

Before going into a comprehensive discussion over the displacement and rehabilitation process of the conflict-related displaced women of Swat and Waziristan, it becomes important to apprehend the variation of conflicts -their reasons and modalities, which varies from society to society. Usually, a conflict arises as a result of social disagreements, a clash of interests and promotion of one's religious/ethnic or political agendas which at times lead to taking up arms and indulging in violent clashes. Insurgencies, civil wars and terrorist attacks are some of the manifestations of the conflict, which in turn perturbs the social order, thus dislocating the routine of the residents. In such circumstances, the most vulnerable are women and children, regardless of their social structure. The sufferings of this weaker section of society are more or less the same, no matter where it occurs and how divergent a conflict is. It is important to note that the recognition of women rights in a conflict situation is a recent hybrid warfare phenomenon, developed over time. The literature available on the conflict remained gender blind in the past. It has developed rapidly in the last twenty years, including the impact of war on women and girls by keeping in view their vulnerability and capacity as female gender. The previous research on gender and conflict hail from various fields ranging from anthropology, law and gender studies but they do not speak of the broader dynamics of conflict in a global context. Thus, the focus was on the conflict in a specific time and place and its subsequent effects on women, men and their relationships. Particularly, after the violent breakup of Yugoslavia (1990s) and the genocide in Rwanda (1994), the lobbying by mobilized translational women's rights 
movement and human rights groups, along with media campaign, the widespread and systematic violence against women was seriously debated. ${ }^{3}$ Today, various kinds of atrocities against women in conflict zones, both during displacement and rehabilitation process has become a part of various studies. While explaining the nature of internal conflicts and their impact on women, Kaufman and Williams write:

Societies do not erupt into internal conflicts -- ethnic, civil, and/or religious wars -- without some prior warning or notice. Often the changes that take place within the society have the greatest impact on women, who are most sensitive to those changes. Yet, women have the least amount of access to the political system and therefore the least opportunity to make or even influence the decisions that could avert conflict. Their options, once conflict begins are limited: to stay and hope that they can survive the conflict, to leave and become a refugee, or to engage in some form of political action either in support of the conflict or working to end the conflict, which also can help set the stage for the post-conflict society. ${ }^{4}$

Nevertheless, in domestically strong patriarchal societies like that of Swat and Waziristan, there is less chance that women become a part of any political solution to support or oppose the conflict as hinted by Kaufman and Williams. These women are neither equipped with education nor supported by a male-dominant structure to be decisive about the prevailed conflict. Our scope of research goes beyond the concept presented by the mentioned authors, as our primary concern is to understand the challenges faced by the community in a post-conflict environment, accepting that

${ }^{3}$ Aoláin, Fionnuala Ní, Naomi R. Cahn, Dina Francesca Haynes, and Nahla Valji, eds, The Oxford Handbook of Gender and Conflict (Oxford University Press, 2018), xxxv-xxxvii.

${ }^{4}$ Kaufman, Joyce P., and Kristen P. Williams, Women and War: Gender Identity and Activism in Times of Conflict. (Kumarian Press, 2010), 58. 
women have little or no control over the decision-making process to avoid a conflict. In the majority of the cases, the vulnerability of the female gender during and after a conflict is of acute nature, posing various challenges of multifarious nature, even though women are not the ones, who initiate wars. While explaining this notion, a former Executive Director of the United Nations Population Fund (UNFPA), Thoraya Ahmed Obaid stated, "women rarely wage war, but they too often suffer the worst of its consequences. Gender-based violence, including rape, is a repugnant and increasingly familiar weapon of war. It extends far beyond its direct victims, insidiously tearing apart families and shattering societies for generations to come." 5 Two recent examples of gross women rights violations in a conflict situation are Syrian and Yemeni women. In the wake of the Syrian conflict, there are approximately 250,000 causalities during the civil strife, starting as a part of Arab Spring in 2011. Although, majority of sufferers were men, whereas four million became refugees. Estimates say around 7.6 million were forced to leave their homes and took shelter in various parts of the country. However, as expected, Syrian women suffered the most due to financial crisis. Most serious suffering came in the shape of forced early age marriages, in which these girls became the victim of domestic abuse. ${ }^{6}$ The matter of fact is that even in these combat zones, women are considered physically weak and financially dependent, thus becoming an easy tool of aggression and suffering in war-torn areas. Similarly, since 2015, as a result of the Yemen conflict, the country faced the worst kind of human violations. According to the United Nations Humanitarian Needs Overview, "(Yemen)... already exhibit the highest maternal death rates in the Arab region, because of the

5 "UNFPA launches State of the World Population 2010 - NGLS interviews lead author of the report Barbara Crossette," February 17, 2016, https://www.unngls.org/index.php/un-ngls_news_archives/2010/746-unfpa-launches-state-of-theworld-population-2010- $\% \mathrm{E} 2 \% 80 \% 93$-ngls-interviews-lead-author-of-the-reportbarbara-crossette

${ }^{6}$ Hibaaq Osman, "This is the Brutal Effect of War on the Women of Syria", Independent, January 29, 2016, Retrieved from, $\mathrm{http}: / / \mathrm{www}$. independent.co.uk/voices/this-is-the-brutal-effect-of-war-on-the-women-ofsyria-a6841856.html 
scarcity of food due to conflict put the lives of 352,000 pregnant women at risk. Medical supplies are in chronically short supply. Only 45 per cent of health facilities are functioning, and only 35 per cent of these provide maternal and newborn services." 7

Similarly, in South Asia, women faced a variety of hardships during and after a conflict, no matter whether they are Rohingya refugees in Bangladesh, Afghans in Pakistan, Tamils in India, internally displaced in Sri Lanka or Bhutanese in Nepal. In all these cases, women are seen with small children clinging to their mothers or elder sisters. They are largely seen as non-subjects due to the patriarchal structure of the respective societies. Their identity is overshadowed into a similar category of victim and community and they are unable to represent themselves. The most relevant example is 30 years' civil war waged by the Liberation Tigers of Tamil Eelam (LTTE) in Sri Lanka (1983-2009), resulting in the sufferings of women and children on one side, while their large-scale displacement on the other. According to a report by the prestigious "International Crisis Group" around 40,000 Tamils were displaced and roughly 40,000 "war widows" lived in the Northern Province and 50,000 in the east of the country. Thus, Tamil women of North and East are the real sufferers of this conflict. These widows and wives of the missing had no choice but to adopt to their new role as bread earners, leaving their culturally defined traditional placement in a patriarchal society. ${ }^{8}$ Another example of women displacement and suffering in South Asia is the 1971 civil war in East Pakistan (Bangladesh), where again women and children on both sides of the civil war suffered, even though they were not part of the conflict. ${ }^{9}$

7 "At Two-year Mark, Yemen's Conflict takes Heavy Toll on Women and Girls", United Nations Population Fund, March 23, 2017,

http://www.unfpa.org/news/two-year-mark-yemens-conflict-takes-heavy-toll-womenand-girls

8 "Sri Lanka's Conflict-Affected Women: Dealing with the Legacy of War,"

International Crisis Group, July 28, 2017, https://www.crisisgroup.org/asia/southasia/sri-lanka/289-sri-lankas-conflict-affected-women-dealing-legacy-war

${ }^{9}$ Sarmila Bose, Dead Reckoning: Memories of the 1971 Bangladesh War.

(Columbia University Press, 2011). 


\section{Dr Farooq Hasnat \& Dr Shehzadi Zamurrad Awan}

Keeping in view the above discussed few examples of women miseries in war zones of the Middle East and South Asia, this research will be carried out from three angles.

First, it will attempt to understand the centuries-old tribal customs and traditions of the Swat and Waziristan area, which confine women in an isolated and non-participatory role as compared to the mainstream of Pakistani women.

The second dimension of this research is to compare and contrast the dynamics and magnitude of conflicts in Swat and Waziristan and their impact on women of these areas.

The third segment of this research is to investigate the accumulated challenges of Swati and Waziri women in the displacement and rehabilitation process.

\section{Women Placement in Socio-cultural Set-up of Waziristan and Swat}

Waziristan: Waziristan is among one of the seven tribal agencies of FATA, bordering Afghanistan. It occupies 15,000 square kilometres of land, with approximately 791,087 inhabitants, mostly populated by Pashtun tribes. For administrative purposes, Waziristan is divided into two parts: North Waziristan and South Waziristan. The people of Waziristan adhere to unanimously agreed unwritten code of law Wazirwalla, locally known as Waziri qanun. The tribal elders, who are members of the Jirga, make decisions according to the Wazirwalla. When the British established their colonial rule in South Asia, considering the independent nature of the tribes, they opted to adopt the system, confining and respecting the already existing tribal customs. In this context, they introduced Frontier 
Crimes Regulation (FCR), ${ }^{10}$ to govern these areas. These jirgas became a parallel system of authority but women were ignored and did not become a part of the hybrid British colonial system. Even under British control, they remained subservient as before. This situation continued even after 1947, when they became part of Pakistan.

This situation is better explained by a scholar on Tribal areas, Akbar S. Ahmed, as he states,

"Waziristan society is male-dominated. Women enjoy almost no rights and do not inherit land or property. A woman fetches from 10,000 to 40,000 rupees in brideprice, most of which is kept by her father. "Il According to FATA Secretariat 2013 report, in North Waziristan, the girl's enrollment at Primary, Middle and High school were 29,825 and six respectively, whereas, in South Waziristan, it was 111,18 and five. ${ }^{12}$

The female literacy rate in Waziristan remains disappointing, as in the year of 2011-12, in the South, $7.5 \%$, whereas in the North just $4.26 \%$ girls were enrolled. ${ }^{13}$ In an environment, where there is negligible literacy and a stronghold of tribal customs and traditions; radicalization further worsened the situation particularly for women. Although in Pashtun code of life, natively known as "Pashthunwali", theoretically women enjoy great respect but for all practical purposes, they are not considered a part

10 There were exceptions to the FCR, when compare to the rest of judicial system in Pakistan. For example, the basic ingredients of law which are right to appeal, appoint an attorney and present an argument were absent.

${ }^{11}$ Akbar S. Ahmed, "Religion and Politics in Muslim Society: Order and Conflict in Pakistan," (Cambridge University Press, 1983), 27.

${ }^{12}$ Education Sector Analysis of the Federally Administered Tribal Areas (FATA) of Pakistan, Directorate of Education, FATA FATA Secretariat Warsak Road, Peshawar, 2013. https://www.academia.edu/6052729/Education_Sector_Analysis_Report_FATA Education_Sector_Analysis_of_the_Federally_Administered_Tribal_Areas_FATA_of_ Pakistan_Directorate_of_Education_FATA_FATA_SecretariatAugust, $201 \overline{3}$.

13 "Fata Sees Modest Increase in Literacy", Dawn, April 01, 2014. 


\section{Dr Farooq Hasnat \& Dr Shehzadi Zamurrad Awan}

of the mainstream society. The subservient women role is not only because of the patriarchal design of Pashtun culture but is also reinforced by state policies in socio-economic and political spheres. While further explaining, resident scholars of these areas, Inamullah Marwat and Rafiud-din Mahsud wrote, "women in FATA hardly cast vote, and consequently, politically they are inactive. Their participation in politics is discouraged, courtesy the pashthun code of life, but government too has not made any real attempt to break the status quo by constitutionally allocating a few reserved seats to women in FATA like every other province." ${ }^{14}$ Similarly in the social sector, women have no say in marriage and divorce-related matters and their mobility is also restricted.

The environment for women became more hostile after militants started to dominate the area since 2002. Instead of the traditional heads, the clerics took over the decision making. They mixed culture with their limited understanding of Islam. Thus, their imposed "Shariah," forced women to cover their faces and forbid them from leaving homes without the company of a male family member. Such strict rulings further refrained females from participation, may it be culture or politics. ${ }^{15}$ This transformation is well explained by a local writer, Rafiuddin Mehsud, who explains the women marginalization during Talibanization. Mehsud states, “ 'Baragai Attan' was a traditional dance in which men and women danced, singing songs or 'tapas' to the beat of drums, usually at weddings. It started vanishing during Afghan war times and particularly due to the emergence of Talibanization in the area after the outrageous incident of $9 / 11 \ldots$ Culture is a reflection of the lives people live; however, very sadly, the whole culture is at stake because of militancy and no media coverage in South Waziristan. South Waziristan remains under siege socially and culturally, while the rest of Pakistan conveniently ignores

${ }^{14}$ Inamullah Marwat and Rafi-ud-din Mahsud, "Challenges faced by women in FATA", Daily Times, August 05, 2016.

${ }^{15}$ Zulfiqar Ali, "Secular roots: Waziristan in retrospect", The ExpressTribune, May 3, 2015. 
that. It too, was once a place where music, dance and colour were an integral part of its culture." 16

Swat: The beautiful valley of semi-tribal Swat is located in the Malakand Division of PATA. As the third-largest district, it is a part of the province of Khyber Pakhtunkhwa. According to 2017 unofficial census reports, it has a population of 2.31 million, mostly inhabited by Yusufzai Pathans. As a Pashtun society, like Waziristan, Swat also adheres to the principles of Pakhtunwali, where the centuries-old institution of Jirga (tribal council of male elders) is responsible for the resolution of all kinds of issues. Nevertheless, the history of Swat, in terms of radicalization and women's status is quite different from that of Waziristan. Even in 1915, when Swat was a princely state, its women were able to receive a share from the profit of land, though insignificant. Although traditionally, the people of Swat had a religious inclination since the beginning, the extremist version of religion was introduced after the rise of Tehreek-e-Nafaz-e-Shariat-eMohammadi-TNSM, led by Sufi Muhammad (a militant group, having close links with Taliban) in the 1990s. TNSM declared education of women "un-Islamic" and restricted female mobility. While highlighting directives of the Tehreek, Lubna Nazir Chaudhary writes, "between 2004 and 2007, Fazlullah set up illegal FM stations. Its target audience were the women in Swat. Initially the broadcasts were about educating women about Islam and pointing out their responsibilities and duties as good Muslims, which included making sure the men went to the mosque five times a day, grew their beard, and wore appropriate clothes." ${ }^{17}$ According to the Swat education department, as a result of Mullah Fazlullah (Son-inLaw of Sufi Muhammad) speeches on his FM radio, more than 30 per cent of girls were dropped out of education institutions in 2006 and 2007. According to the Pakistan Bureau of Statistics, the literacy Ratio in Swat

\footnotetext{
${ }^{16}$ Rafiuddin Mehsud, "The lost culture of South Waziristan Agency, Fata”, Daily Times, May 24, 2016.

${ }^{17}$ Lubna Nazir Chaudhry, "Women in Post-Conflict Swat, Pakistan: Notes on Agency, Resistance, and Survival," in Asian Muslim Women: Globalization and Local Realities, ed. Huma Ahmed-Ghosh (SUNY Press, 2015), 86.
} 
is $28.75 \% ; 43.16 \%$ for male and $13.45 \%$ for female, respectively. ${ }^{18}$ Although overall literacy and the male/female percentages are not encouraging yet when we compare it with that of Waziristan, Swati women in comparison with their Waziri sisters are better off.

\section{Conflict of Waziristan/Swat and its Impact on Women}

As discussed above, the conservative traditional society of Waziristan was already socio-economically deprived along with the weak writ of state authority and inadequate infrastructure; thus, providing a conducive environment to extremist elements to make their space in 2002. Consequently, Al-Qaeda and Taliban elements slipped into this region. While writing about the roots of extremism in Waziristan, a professor of politics, Farooq Hasnat explains:

After the dismantling of the Taliban regime by the US military, many Al-Qaeda and Taliban fugitives entered the tribal areas of Pakistan and became welcome guests of the local tribes....Initially, the Pakistan-based Taliban gathered in South Waziristan, but later spread to other agencies of FATA. They were successful in establishing close relations with the locals on the basis of ideology, marriage, and money. For example, the successor of Osama Bin Laden, Ayman al-Zawahiri married to the Mamond tribe of Bajaur Agency. ${ }^{19}$

Gradually, these extremists started to replace the centuries-old tribal system of Malik and Political Agent with militant Mullahs, who gave judgements as per their interpretation of religion. In this situation, the Waziri women, who were already facing gender segregation because of

18 "Swat District at a Glance", Pakistan Beauru of Statistics, http://www.pbs.gov.pk/sites/default/files//tables/District $\% 20$ at $\% 20 \mathrm{a} \% 20$ glance $\% 20$ Swa t.pdf

${ }^{19}$ Syed Farooq Hasnat, Global Security Watch - Pakistan (Praeger, 2011), 152153. 
conservative socio-cultural norms, further felt their spaces to be reduced. The Taliban style of restrictions included the enforcement of the dress code in the shape of Burqa. ${ }^{20}$ Here it is important to understand that though Burqa as a religious or/and personal choice even existed before the Taliban, it was neither mandatory to observe nor the women were punished in Taliban style for any such omission.

The miseries of Waziri women were many even before the start of the conflict in 2002. The situation worsensed just before the pre-conflict era, where society came under tremendous pressure and provided space to the militants, undermining the role of the century's old tradition. Thus, women suffered most by losing their already limited liberties. The condition of Swati women, however, was different from their Waziri counterparts during conflict environment. Many reasons can be explained for this situation. First was Swat's better infrastructure in terms of schools, hospitals, water, electricity and sanitation systems. Secondly, the Waziri women were worse as unlike their Swati counterparts, they entirely relied on men, including finances. They even had to seek permission from their male members for going to places outside their homes. The Waziri women's entire universe was their household and looking after the children as well as socializing with the close family. The already marginalized status further received a setback with the introduction of militancy. In comparison, before the introduction of militant culture, the Swati women had more rights and their mobility was not as restricted as those of the Waziris. They attended schools, took acceptable jobs (banks, government departments and NGOs) and were free to go for such outings as shopping. With the control of Sufi Mohammad over the area and the influence of Talibanization, even these "concessions" became limited. While comparing the condition of women from both areas, one of the respondents from Swat in a group discussion shared:

Women in Swat before the military operation in 2007, were getting education and also involved in the job

\footnotetext{
${ }^{20}$ A voluminous outer garment that covers them from head to toe.
} 
market, thus their challenges were less as compared to the women of Waziristan. Moreover, in Swat many men are working in the Middles Eastern countries, thus their women were already taking care of many responsibilities outside the home. When the operation started and displacement began, they were able to manage the situation better as compared to Waziri women. (Nawabzada Junaid Khan-Swat)

While further assessing women's situation during Talibanisation in Swat, Zeenia Faraz writes, "Violent extremism has adversely affected women's mobility, especially in Khyber Pakhtunkhwa Province (KP). In Swat, for example, the Taliban banned women from working altogether and from leaving the house unless accompanied by a male family member. This affected not only women's access to health-care facilities in the region but also household incomes." ${ }^{21}$ Nevertheless, the restricted female mobility resulted in negligence towards their education in both areas. After the incoming of Islamist militant groups in these areas, women spaces were further reduced in the tribal society. Thus, these religious-cultural handicaps made them incapable to deal with the challenges attached to displacement and the rehabilitation process, which would be discussed in the forthcoming segment.

\section{Challenges and Rehabilitation for Displaced Women of Swat and Waziristan:}

In two years, i.e., between 2007 and 2009, the militant groups in Swat and Waziristan were able to exercise their near-complete control. They challenged the security forces, along with those groups, which supported the government. To control the situation, the government of Pakistan

${ }^{21}$ Zeenia Faraz, "Women, Peace, and Security in Pakistan", United States Institute of Peace-Peace Brief, February 15, 2017, https://reliefweb.int/ sites/reliefweb.int/files/resources/PB218-Women-Peace-and-Security-in-Pakistan.pdf. 
Pakistani Semi-tribal/Tribal Women in War Zones: Displacement...

launched military operations against the militants in FATA and PATA areas, as mentioned in Table 1.

\section{Table 1: Military Operations in FATA and PATA}

\begin{tabular}{|l|l|l|}
\hline Date & Name of Operations & \multicolumn{1}{l|}{ FATA/PATA Area } \\
\hline $\mathbf{2 0 0 7}$ & Rah-i-Haq-I & Swat \& Shangla \\
\hline $\mathbf{2 0 0 8}$ & Rah-i-Haq-II & Swat \& Shangla \\
\hline $\mathbf{2 0 0 8}$ & Sirat-i-Mustaqeem & Khyber Agency \\
\hline $\mathbf{2 0 0 8}$ & Sher Dil & Bajaur Agency \\
\hline $\mathbf{2 0 0 8}$ & Sirat-Mustaqeem & Khyber Agency \\
\hline $\mathbf{2 0 0 9}$ & Rah-i-Haq-III & Swat \& Shangla \\
\hline $\mathbf{2 0 0 9}$ & Black Thunderstorm & Buner, Lower Dir \& Shangla \\
\hline $\mathbf{2 0 0 9}$ & Rah-e-Najat & South Waziristan \\
\hline $\mathbf{2 0 0 9}$ & Brekhna & Mohamand Agency \\
\hline $\mathbf{2 0 0 9}$ & Rah-i- Rast & Swat \\
\hline $\mathbf{2 0 1 4}$ & Zarb-Azb & North Waziristan \\
\hline
\end{tabular}

Source: Kashif Abbasi, "Chronology of Military Operations", Dawn, June 16, 2014.

As a result of the mentioned military operations against militants, a large number of the residents of these areas were displaced. According to Human Rights Commission 2010 report, as a result of the army operation in FATA and PATA, around 2.7 million people were displaced. While writing about the number of Internally Displaced Persons (IDPs) in the wake of conflict and their rehabilitation, the United States Department of State and the Broadcasting Board of Governors States:

By July 2009, the number of IDPs was adjusted to 2.3 million as the National Database and Regional Authority in Pakistan verified the IDPs' status and information. In 
the same month, the Government of Pakistan declared many areas in the Swat and Buner districts safe for return and initiated the return process. The Government of Pakistan provided transportation, security, and essential supplies to returnees, with the assistance of humanitarian organizations. By October 2009, more than 1.6 million IDPs who had been living in camps and host communities returned to their homes. ${ }^{22}$

The first challenge for these IDPs was to shift them involuntarily in relief camps and host communities. A large number of IDPs avoided living in government camps as their women were shy to reside in the vicinity of strangers. Therefore, they opted for rented accommodations. Only where there was no such facility, the camps became their option. There was a problem when it came to identifying the exact number of displaced persons, as women, in particular, did not come forward for this purpose. Secondly, those who were displaced from non-calamity areas were not counted, in the first place. While sharing his feeling of grief and uncertainty, Abdullah, a resident of Swat explained, "Swatis were not expecting it, but were suddenly caught up in violence -- as if a sleeping person was attacked with a knife...This destroyed life there. Markets, hospitals, and schools were shut down and militants would roam around in groups of hundreds. The police force stopped working altogether, and the courts were forced to close down, too. It was difficult to live under such circumstances, so most people in Swat, including us, were forced to scatter into different regions."23 After leaving everything back home,

22 “Bureau of Population, Refugees and Migration's Internally Displaced Persons Program in Pakistan," United States Department of State and the Broad casting Board of Governors, Office of the Inspector General, Report Number MERO1-11-01. January, 2011,11,

${ }^{23}$ Abubakar Siddique, "Swat Valley's displaced between Hope and Fear in Pakistan", Radio Free Europe/Radio Liberty, July 10, 2009, https://www.rferl. org/a/Swat_Valleys_Displaced_Between_Hope_And_Fear_In_Pakistan/1773979.html. 
including homes, cattle and businesses, most of them were living in tented camps, located in Mardan and Swabi. This forced displacement was more challenging for women of semi-tribal society, as they were socioculturally dependent on males and had no exposure to the world outside their homes. Now after the displacement, these women were bound to live in relief camps under tents, were in the first place, for them to preserve privacy became difficult, which is a prime concern for tribal life-structure. While explaining the condition of Swati people during migration and displacement, a respondent in a group discussion shared:

In Swat, when the military operation started, people migrated where their relatives lived, in different cities. In my own home, which is in Lahore, we hosted relatives, consisting of 20 families from Swat. For IDPs, the government had established various camps but they wanted to live with their relatives as they felt safer there and they thought their privacy can only be maintained by staying with relatives. (Nawabzada Junaid Khan: Swat)

Another respondent from Waziristan in a group discussion shared the trauma of displacement, which shocked the residents, especially females. He recalled:

When in 2009, a military operation against the militants, in South Waziristan started, the inhabitants of this area were asked to migrate. Among them, were a good percentage of children, women, and senior citizens.

Roads were blocked, the terrain was difficult and weather was cold. They had to travel on foot for miles,

because of the blockade of roads, due to military operation. Pregnant women faced immense challenges.

Many died during their travel because of premature deliveries. Many children and old people also died while migrating, as it took many days to travel, and with great 
difficulty, they managed to reach such settled areas as D.I Khan and Karachi. When they reached these settled areas, they contacted their relatives in these places and, instead of staying in government settled camps, they preferred their relative's homes. (Raza Khan: South Waziristan)

The above narration of the eye-witness highlights the miseries of women with health issues that multiplied during the displacement process. While writing about the challenges these displaced women, including the pregnant females, faced in relief camps, Samar Minallah writes, "A large number of women and children have been affected by health-related problems that are largely not addressed. Premature births, pregnancy complications and a high prevalence of infant mortality, are some of the consequences that are yet to be fully tackled. An unnoticed aspect of displacement is the loss of privacy and 'honour' of womenfolk. This has further confined women to the stifling tents in the camps." 24 There can be an argument that for these women, living in tents should not be a big problem, but one needs to understand that for a tribal female, her house is her domain, and her life revolves around different household chores. Minallah further explains, "Back home, these women would go out to pick 'saaba' (spinach), wash clothes at the stream ('goodar') and move around to attend social and cultural events.... For every woman here, 'home' remained her domain, her kingdom. The plants she watered, the chickens she fed, the dung-cakes she slapped on the walls, all provided a feeling of purpose." ${ }^{25}$ When these women were displaced and lived in camps, the majority of them suffered from the feeling of alienation and hopelessness, which resulted in anxiety and depression. While sharing her feelings in camps, a displaced woman from Buner, Farhat Bibi expressed,

\footnotetext{
${ }^{24}$ Samar Minallah, "Internally Displaced Women: Problems and Needs", Legislative Watch-Aurat Foundation, Issue 28, April-June, 2009,1 ${ }^{25}$ Ibid.
} 
"I feel exposed like a pot without a lid. Anyone can come and interfere." 26 Similar emotions were shared by one of the respondents in a group discussion, as he explained:

It is obvious when you migrate, you go through a cultural shock and when you return, you again face counter-cultural shock. To live in urban cities like Karachi and Lahore after the migration was challenging. But when they returned, they were disappointed to see their destroyed houses, blown-up pipelines and damaged irrigation system. (Uzair Gul: Waziristan)

Majority of challenges for displaced Swati and Waziri women in one way or another were linked with their limited exposure due to the conservative socio-cultural environment. Thus, after displacement, the second biggest challenge for Waziri women was to adjust to a new setting, especially in a situation, where they lost male family members in insurgent attacks. Their complete dependency on males throughout their lives handicapped them, especially while interacting with the male members of the camp for the full-filling of necessities like shelter, clothing and food. Their problems multiply as the majority of these females had no National Identity Cards (NIC), thus remaining unable to receive adequate relief in the shape of cash and food supplies. While shifting to camps, some of them misplaced NIC but many were not even registered as citizens of Pakistan. Acknowledging the absence of NICs as a hindrance in the rehabilitation process, Najam U Din writes:

Since NICs were a mandatory requirement for the registration of the displaced, lack of NICs meant that women were less likely to be able to exercise their rights or access assistance and protection. Women without NICs were not registered or housed at camps, nor were families headed by such women. Women who had misplaced their NICs during their flight were issued

\footnotetext{
${ }^{26}$ Ibid.
} 
copies by mobile teams, but those who had not had their NICs made in their native areas were not entertained. ${ }^{27}$

There are many reasons for this miserable situation. First was lack of education which did not let the residents of these areas accept the female gender as an equal member. Moreover, the element of family honour in these localities is strongly attached to the women conduct and it is considered that if women will go for registration, their name would be known to the stranger, which is against the sanctity of a family. The second was the presence of militant elements, which further curtailed women participation at all levels. Nevertheless, the condition of Swati women was comparatively better because of their already improved literacy and employment position.

The third challenge for displaced women of Swat and Waziristan was a psychological and emotional disturbance, as they went through the trauma of war and witnessed massive destruction of their homes, schools, murder of teachers and loss of their family members and friends. Consequently, after the military operation, when they returned to their homes, they felt alien in their own houses as the environment had undergone drastic changes in the shape of damaged houses and military pickets, which were manned by un-familiar officers and soldiers. This Post-Traumatic Stress Disorder (PTSD) was a serious challenge especially for women and children as the socio-cultural dynamics of the tribal society hardly allow them to engage in various outdoor activities, including treatment from psychiatrists. After a cross-sectional multi-stage random survey of 500 IDP men, women and children of all ages from North Waziristan, from September 2014 to December 2014; a quantitative study concluded that "Anxiety and mistrust are common among conflict-zone residents. Every third person of Waziristan suffers from depressive disorders and a number

${ }^{27}$ Najam U Din, "Internal Displacement in Pakistan: Contemporary Challenges", Human Rights Commission of Pakistan, October 2010, 24. 
of women and children experience recurring nightmares of bloodsplattered bodies of families living in destitution." ${ }^{28}$ While explaining the condition of women and children in a war-torn area, a respondent in a group discussion shared:

When the Taliban came into this area, the terrorist activities increased. Before and after the military operation, during the displacement and rehabilitation process, women and children went through great trauma and their mental health was affected, as well. No mechanism was introduced to deal with their Post Trauma Disorder. (Nosherwan Khan: Swat)

In Waziristan, the post-conflict environment posed many complex challenges in comparison with Swat. These challenges were not only for native people but also for armed forces as the area still was not clear for people to live a normal life. While highlighting the confronted issues, a respondent in a group discussion explained:

In South Waziristan, when people returned to their areas after military operation, approximately 72 Land Mine blasts cases were reported. These mines were either installed by the Taliban or by the army. Before allowing people to return to their homes after the military operation, these mines had not been dismantled. Therefore, the inhabitants of this area suffered a lot and many of them lost their body parts, as a consequence of these blasts. (Raza Khan: Waziristan)

In this situation, important challenge for government and non-government apparatus was to rehabilitate the displaced population by providing them

${ }^{28}$ Abdur Rahman Aleemi, Muhammad Tariq Chaudhry, Muhammad Azeem Qureshi, Roomana Anwar Baqai, "Psychological Vulnerabilities of Internally Displaced Persons in Pakistan and Its Effects on General Community", IBT Journal of Business Studies 11, no. 2, (Fall 2015): 1-15 (09), http://dx.doi. org/10.46745/ilma.jbs.2015.11.02.01. 
adequate socio-economic securities. According to the estimate of the US Department of State:

The displacement crisis in Pakistan is not over. Despite the significant number of returnees, many IDPs are unable or unwilling to return due to fear for their safety, lack of basic services, or limited prospects for restoring incomes. Moreover, from September to December 2009, continuing security operations in the Khyber, South Wazirsitan, Orakzai and Kurrum Agencies in the FATA displaced an estimated additional 400,000 IDPS, expanding the number of remaining IDPs to approximately 1.6 million. As of January 2010, the total number of IDPs, including those who had returned home and those who were still displaced, was 3.2 million. ${ }^{29}$

Here it is important to understand that the rehabilitation of the displaced population of Swat was quicker than Waziristan as the operation against militants of Swat started in 2009 and military forces announced the evacuation earlier. Whereas, the operation against militants of South Waziristan started in 2009 with the name of Rah-e-Najat. However, in North Waziristan, the military operation was called Zarb-e-Azb (started in 2014). The displacement and rehabilitation of Swati women was a coordinated action between national/international organizations and state apparatus. In this regard, as discussed earlier, the improved literacy rate and employment status of Swati women helped them further to cope with the displacement and rehabilitation challenges more amicably than their Waziri sisters. Despite all the sufferings due to displacement, there is also a silver lining where the whole process of displacement and rehabilitation went through a full circle as explained by Noor Elahi:

\footnotetext{
29 “Bureau of Population, Refugees and Migration's Internally Displaced Persons Program in Pakistan", Op.cit.
} 
Pakistani Semi-tribal/Tribal Women in War Zones: Displacement...

....it can be argued that if the militancy conflict and displacement on one side disturbed the socio-cultural network of men and women, then on the other hand it has also developed new networks and raised awareness by the provision of opportunities for revisiting the cultural system in a democratic and modern way. The establishment of Qoomi Jirgas and women Jirga after the conflict are the examples of such efforts, which encouraged both men and women to reorganize and strengthen their network not only to bring peace in society but also take initiative for the development of Swat valley. The government security agencies and NGOs have directly approached and supported these

Jirga committees for the purpose of peace and implementation of development interventions. ${ }^{30}$

Thus, in the case of Swat, we can assert that the rehabilitation process was swift, more coordinated and also attracted international agencies to work for the betterment of displaced women. Another reason which can be accounted for the better rehabilitation process of the displaced population was the active role of international media, which not only highlighted the prevailing dismal condition of the displaced population but also helped to provide relief and assistance.

Contrary to the situation of Swat in a post-conflict environment, Waziri women from North and South became more vulnerable and helpless as the skirmishes between the militants and the Pakistan Army was in full gear. Particularly the residents of North Waziristan are still facing echoes of war and miseries of displacements to a certain degree. Although population of South Waziristan is returning home in a post-conflict situation, but for these tribal women the major challenges are the

\footnotetext{
${ }^{30}$ Noor Elahi, "Militancy, Conflicts and Displacement in Swat Valley of Pakistan: Analysis of Transformation of Social and Cultural Network", International Journal of Humanities and Social Science 05, no. 3 (March 2015): 226-236 (235), http://www.ijhssnet.com/journals/Vol_5_No_3_March_2015/29.pdf
} 
acquisition of rehabilitation of their destroyed homes, emotional recovery, employment opportunities, especially when most of the families lost their male members, before and after the military operation in these regions. Moreover, here, absence of an independent fact-finding commission is also a handicap. In such circumstances, it becomes difficult to correctly estimate the requirements of the affected, both misplaced and then rehabilitated Waziri tribes. The government officials have a tendency to paint a "rosy picture," for every eventuality, thus making any independent inquiry difficult, especially in the public domain. On the contrary, if an unbiased survey is allowed only then it will be possible to correctly assess the problems of the rehabilitated population. Table 2 explains the status of FATA and PATA displaced residents, including women as of year 2014, which was the height of the conflict.

\section{Table2: Displacement in FATA and PATA}

\begin{tabular}{|c|c|}
\hline Affected Groups & Key Figures \\
\hline Total Resident & $35,532,000$ people \\
\hline Population & 27,675,000 People \\
\hline - Khyber & 4,875,000 People \\
\hline Pakhtunkhwa & 840,000 \\
\hline (KP) Province & 1,386,548 People \\
\hline - FATA Province & \\
\hline Total Population in & 456,548 People \\
\hline Conflict affected area & (36,831 families) \\
\hline of North Waziristan & 143,996 \\
\hline Total Affected & 192,442 \\
\hline Population & 930,000 \\
\hline
\end{tabular}

Source: "Pakistan North Waziristan Agency- IDP Crisis Following the Zarb-eAzb Operation", ACAPS Briefing Note, https://reliefweb.int/sites/ reliefweb.int/files/resources/briefing_note_pakistan_displacement june 2014.pdf 


\section{Conclusion:}

To conclude, one may say that women and children become most affected in conflict situations, and in this case, belonging to the areas of NorthWest Pakistan. However, the magnitude of their miseries could have been lessened through proper planning and timely decisions by relevant governmental authorities. Although, before commencing the military operation, the federal government assured that all women and children living in the conflict zone be shifted to safe places, however, the sociopsychological and long-term logistic fallout of their displacement was not taken into full consideration. While emphasizing on the emotional and other aspects of this conflict, Aimal Khattak states, "The winning of minds and hearts of the people is very crucial for any operation. The launching of the operation is relatively easier than the tasks ahead after the operation such as rehabilitation of the millions of IDPs, restoring the means of their livelihood, reconstruction of houses, markets, schools, and hospitals is very important." 31

Secondly, there were number of serious complaints regarding the postconflict logistics of rehabilitation process, especially in Waziristan where adequate housing facilities along with better chances of employment were not available to those, who returned to their homes. While responding to such complaints, Jennifer McKay in her article for Army Newspaper Hilal explains,

"It is no easy feat to resettle two million people. This is a population greater than many medium-sized cities around the world and spread across a large and diverse region. It requires detailed and insightful planning, political will, extensive and complex coordination and logistics, and substantial funding to support the initiatives to help families rebuild their homes, restock their livestock, plant crops, restart their livelihoods

${ }^{31}$ Aimal Khattak ,"The Mass Displacements of Zarb e Azb: IDP Woes”, August 18, 2016, http://www.alternativeperspectives.org/the-mass-displacements-of-zarb-e-azb-idp-woes/ 
and to mend the fragile economy of this extremely disadvantaged region.",32

Thirdly, while relocating women and children; the authorities could have assured that after displacement, families lived together in the same locality so that they could feel the comfort of the known, rather than be fragmented and felt alienated. Such kind of bondage is not only required during displacement but also needed in the resettlement process.

Fourthly, more efforts could have been made so that the returnees could start their "new" lives through improved employment opportunities, as well as incentives for self-help economic activities. McKay well-defined this phenomenon, "Returns will not be sustainable unless people are able to support themselves. Therefore, significant focus is being placed on the restoration of livelihoods to ensure that people can earn a living either through small commercial enterprises or agriculture. Markets and shops could have been established to provide outlets for agricultural and general products. Vocational training courses to enhance skills in various types of repairs and other marketable skills provided along with assistance to start small enterprises." 33

Fifthly, we are of the view that if the affected children receive appropriate educational and emotional support; i.e., during the time of displacement, it could help to buffer the devastating effects of war. In addition, counselling services for women as well as frightened children should be the priority.

As a final comment, we must accept that the dynamics of the tribal culture are rather tricky for women. While sharing his thoughts with the authors, a respondent belonging to Waziristan, emphasized that the conservative

\footnotetext{
32 Jennifer McKay, "Going Home - Zarb-e-Azb \& Beyond", February 21, 2016, Hilal, http://hilal.gov.pk/index.php/layouts/item/1434-going-home-zarb-e-azb-beyond

${ }^{33}$ Jennifer McKay, "Going Home - Zarb-e-Azb \& Beyond", February 21, 2016, Hilal, http://hilal.gov.pk/index.php/layouts/item/1434-going-home-zarb-e-azb-beyond.
} 
society of Swat and Waziristan regard a woman as dependent on men, therefore, the defeat of Talibanization could make little difference for the female gender, unless the population gets more educated. He shared:

The society of Pakhtunkhwa is known as a conservative society and this area is the most conservative, among all. After Talibanization, this region became more conservative. I see no progression and development in this area even after the exit of Taliban. The area is stuck in traditionally rigid norms and practices. It is more conservative than in the past, where the women continue to face restrictions of every nature. (Uzair Gul: Waziristan)

We can assert that on one side, women should be equipped with proper education and adequate training to deal courageously with the challenges of the post-conflict situations, while on the other, male members of the society must realize that well-equipped and motivated women could be an asset, and not a liability in a conflict situation. 